\title{
O afastamento entre Indivíduo e Estado na doutrina neoliberal
}

The gap between the Individual and the State in neoliberal doctrine

La separación entre el individuo y el estado en la doctrina neoliberal

\author{
Vitória Benaci Irusta \\ vitoriabenaci@gmail.com \\ Universidade Federal do Paraná (UFPR) - Brasil \\ https://orcid.org/0000-0001-9106-3207
}

\begin{abstract}
RESUMO
O neoliberalismo se pauta principalmente na questão das liberdades individuais e de oportunidades iguais. No entanto, estudos das manifestações reais da doutrina neoliberal evidenciam uma lacuna entre os benefícios esperados do livre mercado e seu funcionamento de fato. Esse ensaio busca entender essas contradições do neoliberalismo, explorando a maneira pela qual o discurso neoliberal forjou um afastamento entre o Estado e o indivíduo sobre a premissa das liberdades individuais. Com isso, o objetivo é entender como o discurso individualista neoliberal leva ao boicote do papel do Estado e fomenta a desigualdade estrutural. Essa investigação é feita de maneira teórica e qualitativa, com base em um procedimento de revisão bibliográfica. Explora-se a origem do neoliberalismo enquanto ideologia econômica, as suas incompatibilidades na teoria e na prática, a promoção neoliberal do individualismo e o consequente afastamento entre indivíduo e Estado. Conclui-se que o individualismo e a meritocracia pregados pela doutrina neoliberal resultam em uma responsabilização do indivíduo para atuar como empreendedor de si em detrimento da ação e política governamental, em última análise servindo ao interesse privado e acentuando a desigualdade socioeconômica.
\end{abstract}

Palavras-chave: Neoliberalismo. Individualismo. Estado mínimo. Desigualdade estrutural.

\begin{abstract}
Neoliberalism mainly revolves around the issue of individual freedom and equal opportunities. However, studies of the real expressions of neoliberal doctrine show a gap between the expected benefits of the free market and its actual effects. This essay seeks to understand these contradictions, exploring the way in which the neoliberal discourse forged a distance between the State and the individual on the premise of individual freedom. Thus, the objective is to understand how neoliberal individualist discourse drains the State's public role and fosters structural inequality. This investigation is done through a theoretical and qualitative approach, based on literature review. The essay explores the origin of neoliberalism as an economic ideology, the theoretical and practical incompatibilities it presents, the neoliberal promotion of individualism and the consequent separation between the individual and the State. The conclusion is that the individualist and meritocratic ideology defended by neoliberalism serves the purpose of holding the individual responsible as an entrepreneur of himself instead of prioritizing government action and policy, ultimately serving private interests and accentuating socioeconomic inequality.
\end{abstract}

Keywords: Neoliberalism. Individualism. Minimal state. Structural inequality.

\section{RESUMEN}

El neoliberalismo se basa principalmente en el aspecto de las libertades individuales y la igualdad de oportunidades. Sin embargo, los estudios de las manifestaciones reales de la doctrina neoliberal muestran una brecha entre los beneficios esperados del libre mercado y su funcionamiento concreto. Este ensayo busca comprender estas contradicciones, explorando la forma en que el discurso neoliberal forjó una distancia entre el Estado y el individuo sobre la premisa de las libertades individuales. Con esto, el objetivo es comprender cómo el discurso individualista neoliberal conduce a un boicot al papel del Estado y fomenta la desigualdad estructural. Esta investigación se realiza de forma teórica y cualitativa, con base en la revisión de la literatura. Explora el origen del neoliberalismo como ideología económica, sus incompatibilidades en la teoría y la práctica, la promoción individualismo neoliberal y la consiguiente separación entre individuo y Estado. Se concluye que el individualismo y la meritocracia predicados por la doctrina neoliberal dan como resultado la responsabilidad del individuo de actuar como empresario de sí mismo en detrimento de la acción y política gubernamental, sirviendo en última instancia al interés privado y acentuando la desigualdad socioeconómica.

Palabras clave: Neoliberalismo. Individualismo. Estado mínimo. Desigualdad estructural. 


\section{INTRODUÇÃO}

Atualmente, o neoliberalismo é amplamente difundido tanto no pensamento econômico quanto na estruturação ideológica da sociedade e das relações entre indivíduos. De maneira teórica, seu discurso se pauta principalmente na questão da liberdade, seja liberdade econômica, política, individual ou de oportunidades iguais. No entanto, diversos estudos das manifestações reais da doutrina neoliberal evidenciam uma lacuna entre os benefícios esperados do livre mercado na teoria e seus resultados concretos, observados a nível individual e estatal. De fato, as limitações da doutrina neoliberal se sobressaem quando confrontadas com as desigualdades estruturais presentes na sociedade.

O objetivo desse ensaio é analisar de que maneira o discurso neoliberal forjou um afastamento entre o Estado e o indivíduo sob a premissa das liberdades individuais, resultando em uma responsabilização do indivíduo para atuar como empreendedor de si em detrimento da ação e política governamental. A hipótese deste ensaio é que a promoção neoliberal do individualismo e da meritocracia enquanto virtudes se traduzem realmente em um boicote ao papel do Estado de bemestar e na falência dos processos democráticos. Entende-se que a importância desse estudo é demonstrar o impacto da restrição do Estado via o discurso individualista, confrontando os ditames do neoliberalismo com a desigualdade econômica e social vigente.

Para tal, essa investigação se baseará em uma abordagem teórica e qualitativa, adotando o procedimento de revisão bibliográfica. Serão analisados livros e artigos científicos que descrevem as premissas teóricas do neoliberalismo e exploram suas contradições. Ademais, serão incluídos estudos que abordam as origens históricas desse pensamento, assim como aqueles que providenciam dados e reflexões acerca dos seus impactos atuais na sociedade. Com base nessa bibliografia, formula-se uma revisão crítica da relação entre neoliberalismo e Estado mínimo e suas implicações no que diz respeito ao indivíduo. O objetivo do ensaio não é esgotar a vasta bibliografia em torno dessa questão, mas sim fazer uma breve reflexão sobre como essa ideologia contribui para a fragmentação do coletivo e a precarização da relação entre indivíduo e Estado.

Antes de prosseguir, compreende-se que o termo "neoliberalismo" tende a ser utilizado de maneira assimétrica nas ciências sociais (BOAS; GANS-MORSE, 2009). Dessa maneira, cabe esclarecer que a doutrina neoliberal analisada nesse ensaio se refere à ideologia econômica que enaltece a liberdade individual e a primazia do mercado, repudiando a intromissão estatal. Apoia-se na defesa do laissez-faire sob a premissa que a instituição do mercado é aquela que, por excelência, garante a liberdade individual. Esse foco na importância do indivíduo implica um projeto político de diminuição do Estado, visto que, para os defensores dessa doutrina, "o igualitarismo promovido pelo estado do bem-estar destruía a liberdade dos cidadãos e a vitalidade da concorrência" (PAULANI, 1999, p. 120).

Portanto, ao tratar de neoliberalismo, esse ensaio se refere à agenda neoliberal que reduz o papel do Estado na promoção do bem-estar ao mesmo tempo que enfatiza o papel do indivíduo. Ademais, reconhece-se que a lógica competitiva do mercado é estendida a todo o sistema social e o indivíduo é visto como sendo "empreendedor de si", consequentemente responsável por investir em si mesmo (LAZZARATO, 2009). Nesse sentido, a abordagem do ensaio aproxima-se do que Andrade (2019) caracteriza como uma definição foucaultiana do neoliberalismo, ou seja, uma norma na qual a ação individual e estatal passa a ser uma ação empreendedora e pautada pela rentabilidade.

Inicialmente, será feita uma contextualização crítica da origem e difusão da agenda neoliberal nas últimas décadas. Em seguida, serão expostas as incompatibilidades entre o neoliberalismo na teoria e na prática, focando nos elementos que definem e propagam a desigualdade socioeconômica. Por fim, o papel do individualismo será analisado, procurando compreender as funções do indivíduo de acordo com o neoliberalismo e o consequente afastamento do Estado que resulta dessa postura. O ensaio é concluído com uma discussão a respeito da ideologia envolvida nesse debate e o possível significado das políticas públicas nesse contexto. 


\section{ESTADO E INDIVÍDUO NO NEOLIBERALISMO}

\subsection{Origens do neoliberalismo e a agenda de sua difusão}

A origem do neoliberalismo enquanto corrente de pensamento vigente na atualidade advém da ruptura com a tradição keynesiana e com o Estado de bem-estar da época pós-Segunda Guerra Mundial. Como contextualizado por Fiori, o fim da "era de ouro" do crescimento capitalista e a crise da hegemonia norte-americana na década de 1970 levaram a uma oposição ao keynesianismo (1997, p. 107). A contrarrevolução liberal que se sucedeu foi definida por políticas conservadoras de desregulação, cujos fundamentos ideológicos se baseavam no equilíbrio fiscal, na desregulação dos mercados, na abertura das economias nacionais e na privatização dos serviços públicos (idem, $\mathrm{p}$. 116).

O Consenso de Washington de 1989 consolidou esse programa de políticas, além de difundir pelas nações desenvolvidas e emergentes uma "revolução intelectual" pautada nas novas ideias liberal-conservadoras e contrárias aos "excessos estatais" (FIORI, 1997, p. 122). Disseminava-se assim a ideologia pautada no trickle-down economics, ou seja, na crença de que a liberalização reforçaria o capital da classe alta e consequentemente acabaria gerando benefícios para toda a sociedade.

Ao longo das últimas décadas, o neoliberalismo ganhou força e foi adotado pelas principais economias. Contudo, vale ressaltar que a sua vigência no pensamento econômico moderno é consequência não de uma superioridade teórica, mas sim de uma longa campanha orquestrada em oposição aos governos intervencionistas e socialistas: "políticos, magnatas da mídia e servidores públicos foram recrutados em uma série de organizações que estabeleceram o panorama institucional dentro do qual essa contraofensiva do laissez-faire teve êxito" (HENRY, 2008, p. 215, tradução nossa).

Evidencia-se, portanto, que havia uma agenda por trás da ávida promoção do neoliberalismo. Henry demonstra que foram criados think-tanks especificamente para propagar a ideologia do livre mercado e incutir essas ideias no âmbito político; uma vez articuladas essas políticas, elas foram disseminadas para o público através do uso da mídia (2008, p. 218). O esforço em popularizar o laissez-faire, associá-lo à ideia de uma ordem natural e divulgar essa percepção à sociedade provém do interesse de criar um ambiente ideológico receptivo à promoção irrefreada do lucro e do protagonismo das corporações e do capital, em detrimento de gastos sociais e regulações governamentais. Estabelece-se assim a origem e desenvolvimento do Estado neoliberal atual.

\subsection{Inconsistências do neoliberalismo e desigualdade estrutural}

O Estado neoliberal na teoria é bastante diferente do funcionamento do Estado neoliberal na prática. Como conceitua Harvey, "o Estado neoliberal deve favorecer fortes direitos individuais à propriedade privada, o regime de direito e as instituições de mercados de livre funcionamento e do livre comércio. Trata-se de arranjos institucionais considerados essenciais à garantia das liberdades individuais" (2005, p. 37, grifo nosso). A questão da liberdade é central e recorrente na doutrina neoliberal, sendo fundamentalmente um dos seus pilares. Contudo, estudos mais aprofundados da prática neoliberal e de seus impactos reais evidenciam cada vez mais as incongruências nesse pensamento que, em vez de promover a liberdade, levam a uma maior desigualdade e alienação do indivíduo.

Há diversas incompatibilidades do discurso neoliberal com a prática que se destacam: a promoção da competição perfeita enquanto virtude primordial, desconsiderando o peso do poder de monopólio; ou a idealização dos benefícios do mercado livre em um cenário repleto de falhas de mercado, dentre elas as externalidades negativas geradas por empresas e a assimetria de informações que pesa contra os agentes de menor poder (HARVEY, 2005, p. 39). A assimetria de relações de poder que decorre desses fatores e que apenas se intensifica com o passar do tempo 
justifica a afirmação de que "o laissez-faire é uma ideologia útil para proporcionar um disfarce sob o qual grandes corporações estão crescentemente organizando o mundo de acordo com seus próprios interesses e promovendo objetivos particulares e específicos" (HENRY, 2008, p. 218, tradução nossa).

O nosso foco presente, entretanto, estará nos pressupostos meritocráticos do neoliberalismo que impactam diretamente a percepção sobre o indivíduo, e suas limitações quando analisados a partir de uma realidade desigual. Uma das principais premissas neoliberais, por exemplo, é da produtividade marginal do trabalho, ou seja, a concepção que sob condições de competitividade e do livre mercado, o preço recebido pelo trabalho estaria diretamente de acordo com aquilo que o trabalhador produz. Dessa maneira, "a pobreza deve ser resultado de um processo de decisão do indivíduo que prefere o lazer ao trabalho ou que falhou em investir suficientemente em seu capital humano" (HENRY, 2008, p. 221, tradução nossa). Apoiada na individualização, a doutrina neoliberal se concentra no trabalhador isolado dentro do mercado de trabalho, e a regra geral passa a ser a "flexibilidade", através da qual o indivíduo tomaria as próprias decisões de ampliar a venda da sua força de trabalho.

No entanto, Harvey demonstra a fragilidade dessa política em não considerar as desvantagens às quais o trabalhador está exposto - dentre elas, as assimetrias de poder entre o trabalhador individual e o patrão, assim como a ausência de uma mobilidade livre do trabalho. Dentro de um contexto de alto desemprego e baixo poder de barganha do trabalhador, o resultado da flexibilização tende a ser a exploração do trabalho, e de maneira geral "se traduz em baixos salários, crescente insegurança no emprego e, em muitos casos, perdas de benefícios e de proteções ao trabalho" (HARVEY, 2005, p. 43).

O capitalismo liberal meritocrático também ignora as vantagens intangíveis e estruturais que vêm de fatores como educação, herança e classe social. Em teoria, todos teriam chances iguais de escalar a ladeira do sucesso, uma vez que existiria na sociedade a plena igualdade de oportunidades. A livre mobilidade social pressuposta pelo neoliberalismo foi a base teórica do "sonho americano", que se construiu sobre essa premissa de que, independentemente de histórico familiar ou posição econômica e social, o esforço e o trabalho duro determinariam as oportunidades de vida e o sucesso que o indivíduo viria a conquistar.

O que se observa, no entanto, é uma alta correlação positiva entre riqueza e oportunidades de educação e de rendimentos futuros. O trabalho de Stiglitz (2012, p. 36) mostra que há uma probabilidade menor de crianças pobres com sucesso acadêmico se formarem na faculdade do que crianças ricas que falham academicamente; seus dados revelam que cerca de $9 \%$ dos alunos de universidades altamente seletivas vêm da metade mais pobre da sociedade, enquanto $74 \%$ vêm do quartil mais rico. Dentro dessa realidade, Milanovic pontua que existe um monopólio da educação universitária de alta qualidade por parte da classe alta, resultando em uma crença generalizada de que aqueles formados nas universidades mais caras são também intelectualmente superiores (2019, p. 60).

Ainda de acordo com Milanovic, as vantagens de membros da classe alta são transferidas de uma geração a outra, pois os filhos "não apenas recebem dinheiro enquanto os pais estão vivos, herdam riqueza e se beneficiam do seu capital social, como também aproveitam a vantagem inicial da excelente educação que começa logo no jardim de infância" (2019, p. 61, tradução nossa). Stiglitz também enxerga a maneira pela qual diversas vantagens e desvantagens vêm desde o berço, resumindo o conceito da herança de desigualdade na afirmação:

Enquanto as desigualdades parentais de renda e de educação se traduzem diretamente em desigualdades de oportunidade educacional, a desigualdade de oportunidades começa antes mesmo da escola - nas condições que os pobres enfrentam imediatamente antes e depois do nascimento, diferenças na nutrição e na exposição a poluentes ambientais que podem ter efeitos vitalícios. É tão difícil para aqueles que nasceram na pobreza escaparem disso que os economistas até se referem à situação como sendo uma "armadilha da pobreza" (2012, p. 36, tradução nossa). 
As consequências da pobreza e da falta de acesso à educação e outros serviços públicos de qualidade se manifestam não apenas na formação educacional dos indivíduos, como também em outros indicadores sociais. Stiglitz aponta a pobreza como responsável tanto por alterações em padrões e costumes sociais quanto pelos altos níveis de criminalidade e de encarceramento da população nos Estados Unidos (2012, p. 33). Essas deficiências e desigualdades se tornam estruturais e têm a tendência de seguir em um ciclo vicioso quando não confrontadas com intervenção e auxílio estatal.

Contudo, essa intervenção é rejeitada pela ideologia neoliberal, que em seus princípios procura diminuir o âmbito de atuação do Estado. Uma das principais consequências da perda de poder do Estado é a falência dos processos democráticos. De acordo com Monbiot, essa tendência neoliberal de substituição do público pelo privado culmina em uma crise política, que reduz também o poder do voto popular: "a teoria neoliberal defende que as pessoas podem exercer escolhas através do consumo. Porém alguns têm mais para gastar que outros: na democracia dos consumidores e acionistas, os votos não estão igualmente distribuídos" (2016, p. 5, tradução nossa). $\mathrm{O}$ autor destaca em seguida que o resultado disso é um desempoderamento das classes baixa e média.

Essa incompatibilidade do neoliberalismo com a democracia é ressaltada por diversos autores e assume papel crucial na consideração da desigualdade e dos direitos individuais na atualidade. Para Streeck (2013, p. 265), há um conflito irreconciliável entre o mercado capitalista e a política democrática, uma vez que se baseiam em regimes essencialmente conflitivos: de um lado, o princípio supracitado da produtividade marginal, regido pelo mérito e pelas forças de mercado; e de outro, o regime da necessidade social, definido pelas escolhas sociais coletivas. Harvey também alude a esse conflito quando afirma que "os teóricos neoliberais têm uma profunda suspeita com relação à democracia. A governança pelo regime da maioria é considerada uma ameaça potencial aos direitos individuais e às liberdades constitucionais" (2005, p. 38). Aparentemente contraditória, a afirmação se refere à preferência do governo das elites, uma vez que o foco da doutrina neoliberal está na promoção dos interesses corporativos - ou, como pontua Crouch, a energia da ação política se deslocou para uma pequena elite econômica (2013, p. 235).

A influência da elite econômica na democracia é explorada por Milanovic, que disserta a respeito do caso estado-unidense. Para o autor, é evidente que o financiamento dos políticos e das eleições por parte das entidades corporativas são uma maneira dos ricos comprarem políticas econômicas que irão beneficiá-los, como a diminuição dos impostos sobre grandes fortunas e das regulações ao setor corporativo, dentre outras: "Essas políticas, por sua vez, aumentam a probabilidade dos ricos se manterem no topo. Esse é o elo final em uma corrente [que leva à] criação de uma classe alta permanente, ou pelo menos durável, no capitalismo liberal meritocrático" (2019, p. 59, tradução nossa).

Portanto, quando confrontamos o funcionamento do Estado neoliberal na teoria com os seus impactos reais, o que verificamos empiricamente é o contrário do trickle-down: de fato, os ricos que estão subindo à custa dos que estão abaixo (STIGLITZ, 2012, p. 27). Esses fatores estruturais denunciam as falhas e fracassos do neoliberalismo, que por sua vez culminam em níveis crescentes de desigualdade. Como apresentado, as políticas e pressupostos do laissez-faire sustentam e propagam essa estrutura, resultando tanto em uma crise política e social quanto em uma crise do indivíduo e de sua qualidade de vida e capacidade de reprodução.

\subsection{A função do individualismo no Estado neoliberal}

Uma vez que o neoliberalismo condena a intervenção estatal e opera com base na crença de que o livre mercado seria a forma de organização mais eficiente em alocar recursos, a responsabilidade econômica e social é transferida do Estado para o indivíduo, que possuiria a liberdade de ser empreendedor de si. Dessa maneira, caberia ao indivíduo contratar os serviços básicos que necessita, com base em um processo racional de escolha e investimento. 
A substituição do investimento público pelo privado - e, em última análise, da dívida pública pela privada - consiste em um "keynesianismo privatizado", termo cunhado por Crouch. Essa inversão assume a forma de incentivos direcionados aos indivíduos para se endividarem a fim de financiar sua própria educação e moradia. A liberalização financeira do laissez-faire foi protagonista nessa nova onda, uma vez que auxiliava no endividamento individual necessário para tais investimentos. Enquanto isso, o Estado, sob o regime neoliberal de austeridade, se isenta da necessidade de promover políticas públicas para suprir a necessidade social e coletiva desses serviços (STREECK, 2013, p. 274).

Evidentemente, se os arranjos do livre mercado e da abertura à livre competição preconizados pelo neoliberalismo permitem aos indivíduos a máxima liberdade de organizar sua vida material e obter suas próprias conquistas, tudo se resumiria ao esforço individual. A consequência dessa responsabilização é, portanto, que "o sucesso e o fracasso individuais são interpretados em termos de virtudes empreendedoras ou de falhas pessoais [...], em vez de atribuídos a alguma propriedade sistêmica" (HARVEY, 2005, p. 38).

A responsabilidade do indivíduo sobre si mesmo é citada por Harvey como uma das premissas do Estado neoliberal: "cada indivíduo é julgado responsável por suas próprias ações e por seu próprio bem-estar [...]. Esse princípio é aplicado aos domínios do bem-estar social, da educação, da assistência à saúde e até aos regimes previdenciários" (2005, p. 38). Mais adiante, o autor aponta as brechas que são abertas por essa premissa quando aplicada à sociedade:

A determinação neoliberal de devolver toda responsabilidade por seu bem-estar ao indivíduo tem efeitos duplamente deletérios. À medida que reduz os recursos dedicados ao bem-estar social e reduz o seu papel em áreas como a assistência à saúde, o ensino público e a assistência social [...], o Estado vai deixando segmentos sempre crescentes da população expostos ao empobrecimento. A rede de seguridade social é reduzida ao mínimo indispensável em favor de um sistema que acentua a responsabilidade individual. Em geral se atribuem os fracassos pessoais a falhas individuais, e com demasiada frequência a vítima é quem leva a culpa! (idem, p. 43)

Essas tendências evidenciam como o esvaziamento do Estado promovido pela doutrina neoliberal tem impacto direto na vida material do indivíduo. Ainda assim, como pontuamos inicialmente, essas condições convergem diretamente com a agenda do discurso neoliberal - ou seja, promover a ideia individualista de que a liberdade seria também uma liberdade em relação ao Estado: "a liberdade do indivíduo é definida como a liberdade de qualquer forma de autoridade coercitiva - ou, em termos convencionais, o governo" (HENRY, 2008, p. 221, tradução nossa).

Desse ponto de vista, qualquer organização coletivista acabaria por reduzir a liberdade. O resultado disso é uma crise da democracia, como visto anteriormente, assim como a precarização da integração social das sociedades contemporâneas. A prevalência da austeridade e do individualismo implica uma deterioração da capacidade dos Estados de atuarem como mediadores entre os direitos dos cidadãos e os requisitos da acumulação capitalista (STREECK, 2013, p. 282). O próprio conceito de uma sociedade ser apenas um conjunto de indivíduos já denuncia a mentalidade neoliberal, sendo uma fragmentação característica do discurso de "sociedade sem classes" promovido por governos conservadores como os de Margaret Thatcher e Ronald Reagan.

A redefinição do Estado dentro dos parâmetros do neoliberalismo, portanto, implica o seu distanciamento da sociedade civil. O alinhamento das políticas estatais com os ditames dos mercados internacionais força o Estado a adotar severas medidas de consolidação fiscal que, por sua vez, colocam-no em dissonância com as necessidades dos seus cidadãos (STREECK, 2013, p. 283). Por outro lado, à medida que o poder público se distancia da sociedade, ele se aproxima do empresariado. Embora a diminuição do Estado seja pautada essencialmente em um princípio de não-interferência, a manipulação da economia e a intervenção continuam existindo no neoliberalismo - porém, em detrimento dos indivíduos e a favor das corporações:

O cidadão comum pagará - pela consolidação das finanças públicas, pela falência dos Estados estrangeiros, pela taxa crescente de juros da dívida pública e [...] pelo resgate de 
bancos nacionais e internacionais - com sua poupança privada, com cortes nos direitos públicos, com serviços públicos reduzidos e, de uma forma ou de outra, com impostos mais altos (STREECK, 2013, p. 279, tradução nossa).

Em síntese, considerando a questão da reprodução e acentuação da desigualdade dentro do contexto do Estado neoliberal, explanada na seção anterior, e a agenda ideológica do individualismo, abordada acima, cabe questionar até que ponto a liberdade individual é de fato uma liberdade dentro dessas mazelas socioeconômicas.

\section{DISCUSSÃO E CONSIDERAÇÕES FINAIS}

A conclusão principal deste ensaio é que a distância forjada pelo neoliberalismo entre o indivíduo e o Estado decorre de uma agenda ideológica cujo objetivo, em última análise, é reduzir o Estado de bem-estar, responsabilizando o indivíduo pela auto-gestão de serviços essenciais. Esse conflito não seria acidental, mas sim inerente ao plano político neoliberal. Béland (2007, p. 94) descreve precisamente essa intenção ao relembrar que, para promover a agenda política de Thatcher na Inglaterra, os conservadores "mobilizaram um discurso individualista sobre as virtudes econômicas e morais da propriedade pessoal de tal forma a construir a necessidade de uma privatização da política social". Como visto, é possível observar isso através da doutrina e de políticas neoliberais, dentre elas: a substituição de direitos trabalhistas pela terceirização e negociação direta com o patrão; e a contratação individual de serviços essenciais que vão desde educação particular e planos privados de saúde até aposentadoria privada e serviços de segurança particulares.

A estrutura teórica do laissez-faire implica que a desregulação e o livre funcionamento do mercado deveriam levar a uma maior eficiência e a benefícios difundidos por toda a população. No entanto, o que se verifica de fato é uma maior assimetria econômica e polarização social, decorrentes da estagnação econômica, do desemprego, da insatisfação social, e da perda de poder e legitimidade dos governos (FIORI, 1997, p. 127). De um lado existia uma crença de que a globalização poderia homogeneizar e eliminar esses problemas socioeconômicos; porém, há fortes evidências que a globalização aumentaria, e não diminuiria, a importância do papel do Estado em assegurar a proteção social (WEISS, 2000, p. 11).

Portanto, o verdadeiro resultado dessa transferência de responsabilidade é a fragilização do indivíduo. $\mathrm{O}$ esvaziamento do poder e significado dos sindicatos e dos mecanismos eleitorais leva fundamentalmente a uma perda do poder e capacidade coletiva de barganha dos indivíduos. Da mesma maneira, a transferência da dívida pública à dívida privada inevitavelmente traz consigo a transferência do risco. Lazzarato (2009, p. 124) adiciona que essa redistribuição do risco foi reforçada pela financeirização da economia, que inverte as posições do trabalhador assalariado, que antes possuía um maior nível de segurança e garantias, e do empreendedor, cuja função assumia maiores riscos - porém também maiores lucros. Atualmente, a assimetria de riscos é exacerbada, sendo que "[os assalariados] devem depender apenas dos seus rendimentos, frequentemente bloqueados ou erodidos pela redução sistemática dos gastos sociais, enquanto [os empreendedores e acionistas] podem transferir os riscos para o mercado de ações ou para os seguros" (LAZZARATO, 2009, p. 124). Ressalta-se que os riscos assumidos pelo indivíduo não são apenas financeiros, mas também riscos de saúde física e mental, riscos ocupacionais e riscos de acidente, acentuados ainda pela deterioração das condições de trabalho - problema observado frequentemente no âmbito dos trabalhadores terceirizados (MANDARINI; ALVES; STICCA, 2016).

A contradição latente é que, sob a legitimação da doutrina neoliberal, programas sociais estão sendo privados de sua autoridade, enquanto as corporações seguem desfrutando os benefícios do intervencionismo a seu favor (HENRY, 2008, p. 223). Essa aproximação do Estado com o setor privado é pronunciada no neoliberalismo, ao ponto que "os negócios e corporações não só colaboram intimamente com atores do governo como chegam mesmo a assumir um forte papel na 
redação de leis, na determinação das políticas públicas e na implantação de estruturas regulatórias" (HARVEY, 2005, p. 43). Nesse contexto, é inevitável questionar se o Estado pode mesmo ser um promotor das políticas públicas, ou se elas seriam justamente um resultado da articulação do Estado com o processo de acumulação. Para isso, lembramos a afirmação de Crouch: "o Estado tem sido retratado crescentemente como aliado do poder corporativo. Permanece sendo, contudo, o principal canal para contestar esse poder" (2013, p. 236, tradução nossa). Embora reconheça o papel antagônico do Estado neoliberal, o autor demonstra que essa ainda é a única entidade que possui a autoridade e a capacidade de enfrentar os conflitos gerados pelas externalidades negativas de mercado, pois segue sendo o único detentor dos meios legítimos de coerção.

Portanto, por mais que, no neoliberalismo, o Estado tenha se tornado ferramenta do capital em oposição a promotor do bem-estar social, cabe ressaltar que a atuação governamental por meio de políticas públicas ainda possui papel fundamental em garantir a qualidade de vida dos indivíduos e pavimentar o caminho para uma atenuação de desigualdades. Contudo, como esse ensaio procurou demonstrar, há uma incompatibilidade intrínseca nessa premissa: sendo a desigualdade força-motriz do neoliberalismo, e vice-versa, a única maneira de realmente superar o hiato entre o Estado e o coletivo é a superação do neoliberalismo enquanto lógica predominante de organização econômica e social.

\section{REFERÊNCIAS}

ANDRADE, D. P. O que é o neoliberalismo? A renovação do debate nas ciências sociais. Sociedade e Estado, vol. 34, n. 1, 2019, pp. 211-239.

BÉLAND, D. Neoliberalism and Social Policy: The Politics of Ownership. Policy Studies, vol. 28, n. 2, 2007, pp. 91-107.

BOAS, T.C.; GANS-MORSE, J. Neoliberalism: From New Liberal Philosophy to Anti-Liberal Slogan. Studies in Comparative International Development, vol. 44. Disponível em: https://doi.org/10.1007/s12116-0099040-5, fev. 2009, pp. 137-161.

CROUCH, C. From Markets versus States to Corporations versus Civil Society? In: SCHÄFER, A.; STREECK, W. Politics in the Age of Austerity. Cambridge: Polity Press, 2013, pp. 219-238.

FIORI, J. L. Globalização, hegemonia e império. In: TAVARES, M. C.; FIORI, J. L. (orgs.) Poder e dinheiro: Uma economia política da globalização. $7^{\text {a }}$ Edição, Editora Vozes, 1998, pp. 87-147.

HARVEY, D. O Estado neoliberal. In: O neoliberalismo: história e implicações. $5^{\text {a }}$ Edição, São Paulo: Editora Loyola, 2005, pp. 37-48.

HENRY, J. F. The Ideology of the Laissez Faire Program. Journal of Economic Issues, vol. 42, n. 1, mar. 2008, pp. 209-224.

LAZZARATO, M. Neoliberalism in Action: Inequality, Insecurity and the Reconstitution of the Social. Theory, Culture \& Society, vol. 26, n. 6, 2009, pp. 109-133.

MANDARINI, M. B.; ALVES, A. M.; STICCA, M. G. Terceirização e impactos para a saúde e trabalho: uma revisão sistemática da literatura. Revista Psicologia: Organizações e Trabalho, vol. 16, n. 2, abr-jun 2016, pp. 143-152.

MILANOVIC, B. Liberal Meritocratic Capitalism. In: Capitalism, alone: the future of the system that rules the world. Cambridge: Harvard University Press, 2019, pp. 12-66.

MONBIOT, G. Neoliberalism: the ideology at the root of all our problems. The Guardian, Londres, mar. 2016. Seção de Cultura. Disponível em: https://www.theguardian.com/books/2016/apr/15/neolib eralism-ideology-problem-george-monbiot. Acesso em: 20/06/2020.

PAULANI, L. M. Neoliberalismo e Individualismo. Economia e Sociedade, Campinas, vol. 13, dez. 1999, pp. 115-127.

STIGTLIZ, J. E. America's 1 Percent Problem. In: The price of inequality: How Today's Divided Society Endangers Our Future. New York, Londres: W.W. Norton \& Company, 2012, pp. 23-42.

STREECK, W. The crisis in context: democratic capitalism and its contradictions. In: SCHÄFER, A.; STREECK, W. Politics in the Age of Austerity. Cambridge: Polity Press, 2013, pp. 262-286.

WEISS, L. Globalization and State Power. Development and Society, vol. 29, n. 1, jun. 2000, pp. $1-15$. 